\title{
Isolated Aseptic Liquid Filling Method
}

National Cancer Institute

\section{Source}

National Cancer Institute. Isolated Aseptic Liquid Filling Method. NCI Thesaurus. Code C112986.

A process that fills a dosage unit with a liquid, which is performed in a closed environment under sterile conditions and without human intervention. 